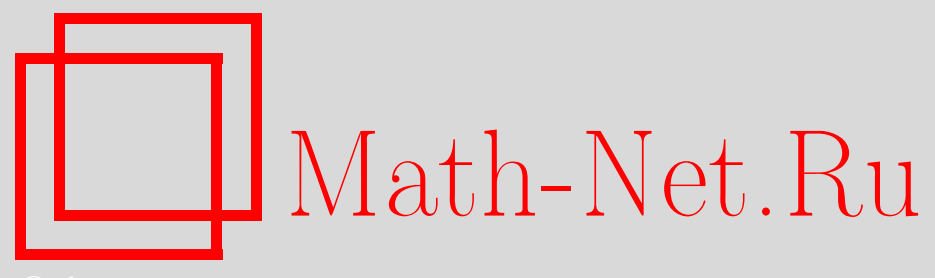

А. Митрофанов, Время жизни шипучей таблетки в стакане воды, Квант, 2021, номер 9, 2-8

DOI: https://doi.org/10.4213/kvant20210901

Использование Общероссийского математического портала Math-Net.Ru подразумевает, что вы прочитали и согласны с пользовательским соглашением http://www . mathnet.ru/rus/agreement

Параметры загрузки:

IP: 3.85 .7 .115

26 апреля 2023 г., 14:00:51 


\section{Время жизни шипучей таблетки в стакане воды}

А.МИТРОФАНОВ

3 А ПОСЛЕДНЕЕ ВРЕМЯ У ЧАСТИ населения возрос интерес к медицинской физике, фармакологии, проблемам здравоохранения и тому подобное. И это не от хорошей жизни. Защитные медицинские маски и перчатки, поголовное измерение температуры у сотрудников на проходных предприятий, сигналы машин скорой помощи и сводки о числе заболевших, авральная, героическая работа медиков и реальные потери людей повлияли на образ жизни, мысли населения и отношение его к медицине и медицинским наукам. Обычные люди (по крайне мере, некоторые мои друзья и знакомые), совсем не врачи, стали задумываться и интересоваться, что же такое антитела, вакцины, вязкость крови, тромбы, антиагреганты (к которым относятся слабые водные растворы ацетилсалициловой кислоты, т.е. аспирина), антикоагулянты (гепарин и др.) и так далее, т.е. темами и понятиями, которые обычно изучают студенты-медики.

В этой статье мы поговорим и поразмышляем (с точки зрения любителя физики) о свойствах таблеток шипучего аспирина и подробнее - о реакции питьевой соды с лимонной кислотой в воде. Именно этот процесс очень часто используется в медицине для транспорта назначенного лекарства к больному органу. Хотелось бы адресовать эту статью не только ценителям безалкогольных шипучих напитков, но и тем бедолагам-больным, которые дома или на больничной койке принимали таблетки шипучего аспирина, чтобы притупить боль или просто временно облегчить свои страдания от болезни.

DOI: https://doi.org/10.4213/kvant20210901

\section{Часть 1}

Англичанин мистер Хопп Смотрит в длинный телескоп. Видит горы и леса, Облака и небеса. Но не видит ничего, Что под носом у него.

Даниил Хармс

Мистер Хопп по-своему прав: удаленные предметы лучше рассматривать в телескоп, бинокль или подзорную трубу. А для наблюдения других объектов существуют другие приборы, например микроскопы. Об окружающем мире можно многое узнать с помощью различных наблюдений и опытов, используя часто простейшие измерительные приборы, такие как весы, линейка, часы или даже обычный градусник. Не говоря уж о доступных в наше время «продвинутых» средствах измерений - GPS-навигаторов, лазерных уровней и дальномеров, ультразвуковых измерителей толщины и эхолотов, различных «умных» датчиков, сенсорных устройствах и так далее.

Мы же попробуем кое-что понять о природе нашего мира (на уровне атомных размеров) из простейших исследований, а именно, из наблюдений, как растворяется таблетка лекарства в стакане воды. К примеру, выясним, как время растворения в воде лекарства - таблетки шипучего аспирина с витамином C - зависит от температуры воды в стакане, и посмотрим, что интересного и поучительного следует из результатов наших нехитрых опытов.

Вы, конечно, замечали, что в теплой воде легче мыть посуду, чем в холодной. И что многие химические реакции или процессы (и не только химические) идут быстрее, когда происходят при более высокой температуре. Лекарства и противови- 
русные вакцины часто хранят в холодильнике, чтобы они на холоде медленнее «старились». Если стаканчик с уже разведенным эпоксидным клеем поместить в сосуд с жидким азотом, то клей быстро не полимеризуется, он замерзнет, но долго будет сохранять свои функциональные свойства, если потом его вытащить из азота и разморозить. С этим хорошо знакомы некоторые бережливые физики-экспериментаторы и их лаборанты.

Кто-то скажет, что это же очевидно. При нагревании веществ скорости молекул или атомов увеличиваются, частицы, которые взаимодействуют друг с другом, чаще сталкиваются и реакции идут быстрее. В действительности все происходит намного сложнее и интереснее. Температурная зависимость скорости процессов совсем (кардинально) другая! И разобраться в этом вопросе нам поможет изучение одной химической реакции, вернее - прямые измерения зависимости ее скорости от температуры среды.

Рассмотрим химическую реакцию растворения в воде лимонной кислоты $\left(\mathrm{C}_{6} \mathrm{H}_{8} \mathrm{O}_{7}\right)$ и питьевой соды (гидрокарбонат натрия $\mathrm{NaHCO}_{3}$ ). Судя по сообщениям из интернета, это самая любимая реакция у школьников, знатоков химии. Именно с ее помощью удается получать простым способом газированный напиток, похожий на лимонад. В сети представлено великое множество рецептов и опытов с лимонной кислотой и питьевой содой, порой очень забавных и поучительных. Для приготовления стакана шипучки (газировки) надо смешать примерно половину чайной ложки лимонной кислоты и чуть меньше половины чайной ложки питьевой соды, залить смесь водой, не забыв добавить и растворить немного сахарного песка или фруктового сиропа для вкуса.

К месту сказать, что отцом современной индустрии безалкогольных напитков принято считать протестантского священника, философа, большого любителя химии и ученого по призванию Джозефа Пристли (1733-1804). Рядом с Лидсом (Англия), где он жил и служил пастором, находился пивоваренный завод, откуда Пристли по-

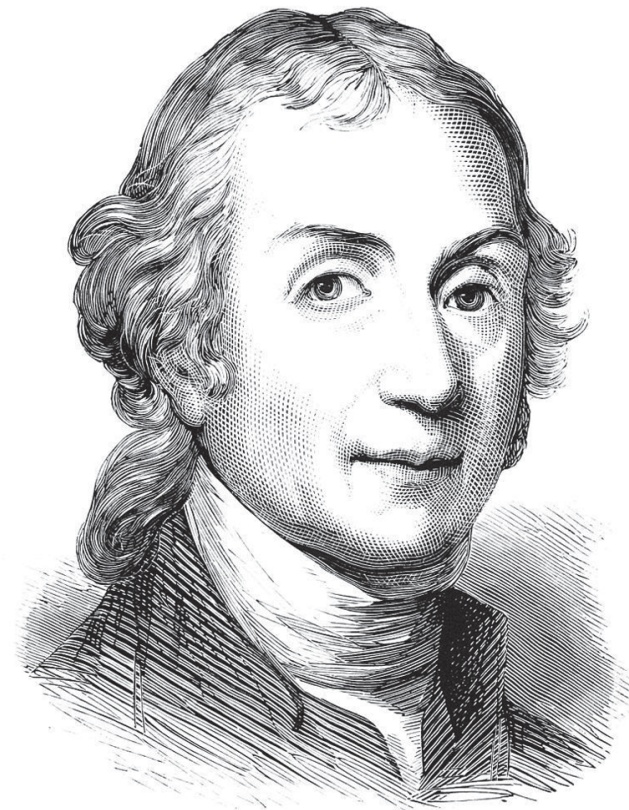

Джозеф Пристли

лучал для своих любительских опытов углекислый газ в нужных ему количествах (этот газ образовывался от брожения пивного сусла в бочках). Наблюдательный священник-химик заметил, что если собирать углекислый газ над водой, то часть газа растворяется в жидкости, что придает ей приятный терпкий привкус. Таким образом Пристли получил (и первым закупорил в бутылку) напиток типа сельтерской или содовой воды. А в истории науки он более известен как ученый, открывший кислород (независимо это открытие сделал шведский химик Карл Вильгельм Шееле, 1742-1786). Пристли открыл также или впервые получил и изучал такие газы, как закись азота, хлористый водород, аммиак, фтористый кремний, диоксид серы и окись углерода. Его работы с газами немало способствовали развитию химической науки. Позднее Джозеф Пристли написал монографию «История учения об электричестве»- труд, за который он был избран почетным членом ряда академий, в том числе Петербургской Академии наук (1780).

Но вернемся к газировке. Конечно, Пристли вряд ли догадывался, какую важную 
роль будут играть потом в жизни людей шипучие газированные напитки. И не мог предвидеть, что 24 апреля даже празднуется Всемирный день газировки. Как сказал один астроном, «открытие нового кулинарного рецепта для человечества бывает порой более важным, чем обнаружение на небе новой звезды».

Химическое уравнение реакции питьевой соды с лимонной кислотой в воде записывается так:

$$
\begin{aligned}
& 3 \mathrm{NaHCO}_{3}+\mathrm{C}_{6} \mathrm{H}_{8} \mathrm{O}_{7}= \\
& =3 \mathrm{CO}_{2}+3 \mathrm{H}_{2} \mathrm{O}+\mathrm{Na}_{3} \mathrm{C}_{6} \mathrm{H}_{5} \mathrm{O}_{7} .
\end{aligned}
$$

В реакции образуется цитрат натрия, углекислый газ и вода. Цитрат натрия $\left(\mathrm{Na}_{3} \mathrm{C}_{6} \mathrm{H}_{5} \mathrm{O}_{7}\right)$ применяется как вкусовая добавка (Е331) в составе газированных напитков и в других продуктах, а также как одна из необходимых составляющих при переливании крови - для предотвращения свертывания донорской крови и ее компонентов.

Когда сухая таблетка опускается в воду, реакция идет достаточно быстро с образованием волшебных пузырьков газа на поверхности таблетки и стакана, которые, всплывая, к тому же шипят, покидая водную поверхность. Часть углекислого газа успевает раствориться в воде. Активная зона реакции находится на поверхности таблетки, именно там рождаются пузырьки углекислого газа. Когда таблетка растворится полностью, выделение пузырьков почти совсем прекращается.

Свойство вещества препятствовать свертыванию крови бывает иногда крайне важным в медицине при лечении тяжелых недугов (например, когда происходит образование сгустков тромбов в мелких сосудах легких при коронавирусной инфекции или в других случаях). Реакция питьевой соды с лимонной кислотой часто используется фармацевтами и химиками-технологами в шипучих таблетках для транспорта разных лекарственных препаратов с водой к пациенту, в том числе антиагрегантов и антикоагулянтов. Лекарственный порошок, растворимый в воде (микрокристаллы витамина С и др.), и водонерастворимый или слабо раство- римый порошок (например, аспирин) прессуются в единую таблетку с питьевой содой и лимонной кислотой (и некоторыми другими добавками). Такие таблетки помещают в легкую герметичную для воды и ее паров многослойную бумажно-полимерную упаковку (иногда алюминизированную с внутренней стороны), защищающую спрессованную смесь порошка от воздействия атмосферной влаги, случайных капель воды и яркого света.

Если вскрыть упаковку и бросить таблетку в стакан с водой, то за короткое время получается раствор или взвесь лекарства в слабо газированном напитке. Так устроены многие шипучие препараты лекарств, например шипучий аспирин-С фирмы Bayer или хорошо известное лекарство АЦЦ Лонг в форме таблеток, применяемых при заболевании органов дыхания. Аналогично устроены таблетки для быстрого приготовления безалкогольных шипучих тонизирующих напитков (энерготоников), витаминов и так далее. Часто в рецептуре шипучих лекарств лимонная кислота и питьевая сода даже не указываются, так как эти вещества и продукты их реакции в воде выполняют только вспомогательную роль.

Простые наблюдения показывают, что время растворения таблетки шипучего аспирина в стакане с водой однозначно зависит от температуры воды - оно резко уменьшается с ростом температуры. Попробуем измерить и изучить эту температурную зависимость. При соблюдении некоторых правил это удается сделать довольно точно и не очень сложно. Запасемся часами с секундной стрелкой (механическими или электронными) с четким (внятным) циферблатом и термометром для измерения температуры воды. А лучше двумя или тремя термометрами, позволяющими точнее измерять температуру и холодной и горячей воды в стакане (в разных температурных диапазонах).

Прежде чем проводить намеченные измерения, нам следует подготовиться к этой работе. Не обсуждая все подробности, заметим, что нам надо научиться приготавливать в сосуде, например в стакане, воду с заданной, но разной температурой, быть уверенным, что в объеме температура воды 
в разных местах практически одинаковая и что при комнатных условиях внешней среды эта температура «не убежит» заметно из-за нагрева или охлаждения окружающим воздухом за время проведения одного измерения (т.е. за «время жизни» таблетки в воде). Температура воды должна быть не только одинаковой по всему объему, но и равняться температуре стенок стакана. Надо также проверить, что у термометров не сбита температурная шкала, а циферблат часов удобен и подходит для надежных фиксаций временны́х интервалов с секундной точностью. Полезен такой подготовительный опыт: исследуйте, как изменяется со временем температура первоначально нагретой (например, кипятка) или охлажденной (в холодильнике) воды при приближении к равновесной комнатной температуре, когда стакан с водой стоит на столе на воздухе.

Мы экспериментировали с таблетками шипучего аспирина-С фирмы Bayer (рис. 1). Указываемая производителем

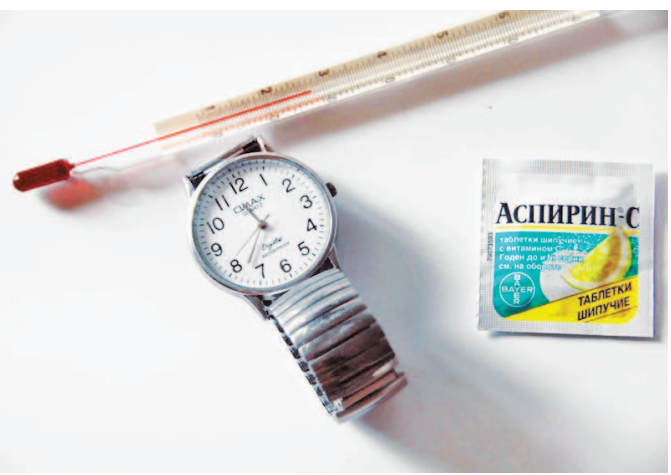

Рис. 1. Термометр, часы и таблетка аспирина-С фирмы Bayer (в упаковке), используемые в опыте

гарантированная герметичность упаковки таблетки более 2 лет. В качестве основного термометра использовался стеклянный градусник ТФ-3-М1, купленный в магазине фототоваров и предназначенный для работы с растворами фотореактивов. Термометр этот без ртути: рабочее вещество- подкрашенная жидкость (видимо, спирт или толуол) в капилляре. Важно, что у этого из- мерителя температуры четкая и чувствительная шкала с ценой деления 0,5 градусов Цельсия. Для опытов при температуре воды вблизи нуля и ближе к точке ее кипения мы брали другие лабораторные градусники с соответствующими шкалами.

Сам опыт состоял в следующем. Устанавливалась равновесная температура воды в почти полном стакане. Затем вскрывался пакетик с шипучим аспирином, и его таблетка опускалась в стакан с водой. Одновременно фиксировалось время начала процесса растворения таблетки. Измерялась длительность растворения таблетки, которая точно фиксировалась визуально с помощью секундной стрелки наручных часов. Заметим, что, перед тем как полностью исчезнуть, таблетка уменьшалась в размерах и всплывала на поверхность воды из-за пузырьков газа, прилипших к поверхности тающей таблетки. Поэтому момент исчезновения плавающей таблетки определялся довольно точно и, как показал опыт, с малым разбросом значений длительности процесса (что очень важно!) при одной и той же температуре воды. После полного (визуального) растворения таблетки в воде еще некоторое, но очень короткое время продолжали выделятся пузырьки газа. Это всплывали прилипшие к стенкам и дну стакана пузырьки и, быть может, продолжалась реакция остатков следов соды и лимонной кислоты, попавших в раствор. Всего от одной таблетки за время реакции выделяется в атмосферу чуть более $100 \mathrm{~cm}^{3}$ углекислого газа (по нашим измерениям с помощью водяного колокола - перевернутого мерного стакана с водой с делениями).

В таблице собраны наши экспериментальные данные, т.е. измеренные времена $(t)$ растворения таблеток шипучего аспирина-С при разных температурах $(\tau)$ воды

«Время жизни» шипучей таблетки аспирина при разных температурах воды в стакане

\begin{tabular}{|l|c|c|c|c|c|c|c|c|c|}
\hline Температура $\tau,{ }^{\circ} \mathrm{C}$ & 63,5 & 50 & 86 & 0 & 18 & 24 & 42,5 & 22,5 & 11,5 \\
\hline Длительность $t$, мин & 0,37 & 0,55 & 0,33 & 9,75 & 2,1 & 1,42 & 0,58 & 1,33 & 3,25 \\
\hline Температура $\tau,{ }^{\circ} \mathrm{C}$ & 15 & 17,5 & 8 & 3,2 & 10 & 30,5 & 20 & 10,5 & 10 \\
\hline Длительность $t$, мин & 2,33 & 1,833 & 4,33 & 6,5 & 3,17 & 0,79 & 1,29 & 3,5 & 3,17 \\
\hline
\end{tabular}



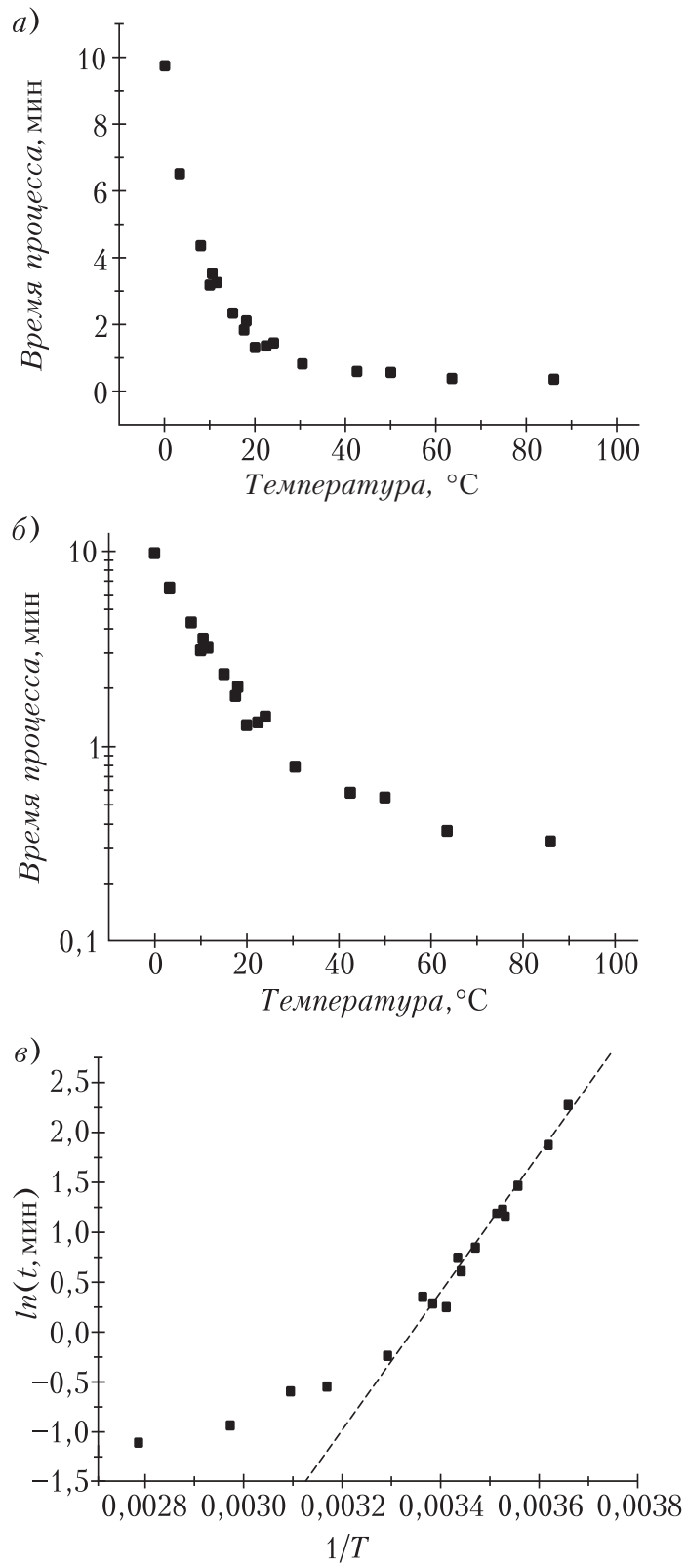

Рис. 2. Температурная зависимость времени растворения шипучей таблетки в стакане воды: а) линейный масштаб по двум осям; б) полулогарифмический масштаб; в) зависимость натурального логарифма времени растворения от обратной абсолютной температуре величины, наклон пунктирной прямой - ее уравнение $y=23,0\left(1-\frac{300}{T}\right)$ - определяет энергию активации в стакане. Длительность процесса растворения указана в минутах.

Сам опыт несложный, его можно проводить даже болея, «добывая» одну - две новые экспериментальные точки в сутки и используя потом лекарство по своему назначению, если это рекомендовал вам лечащий врач.

Раньше, чем делать физические выводы, попробуем найти аналитическую зависимость времени реакции $t$ или ее скорости $v \sim 1 / t$ от температуры. Обычно для построения кривых по экспериментальным данным используются численные значения результатов измерений (в нашем случае данных из таблицы). Но для наглядности результатов часто по экспериментальным точкам строят графики, выбирая удобные шкалы по осям и единицы измерений.

На рисунке 2, $a$ результаты измерений представлены на графике с линейными шкалами по двум осям. Видно, что через экспериментальные точки можно провести гладкую монотонную кривую, вблизи которой лежат все точки с относительно небольшими отклонениями от кривой. При изменении температуры от 0 до $90{ }^{\circ} \mathrm{C}$ «время жизни» таблетки $t$ уменьшается почти в 30 раз, т.е. во столько же раз увеличивается скорость протекания процесса $v$. При высоких температурах скорость реакции, как видно из графика, растет с температурой, но не так быстро, как для реакции в холодной воде.

Чтобы подробнее рассмотреть эти части результатов (для горячей и холодной воды), представим данные в полулогарифмическом масштабе (рис. 2,б). На этом графике видно, что в диапазоне температур $0-30{ }^{\circ} \mathrm{C}$ зависимость скорости от температуры - это с высокой точностью экспонента. Выше этих температур зависимость скорости процесса по сравнению с экспонентой более плавная.

Сделаем еще один шаг. В термодинамике и теплофизике часто температуру измеряют не в градусах Цельсия и обозначают $\tau$, а в абсолютной шкале в градусах Кельвина и обозначают $T$, при этом $T=T_{0}+\tau$, где $T_{0}=273,15$. Чтобы изменить знак наклона кривой $t(T)$ и сдвинуть ее по оси абсцисс, будем отсчитывать не абсолют- 
ную температуру, а обратную ей величину 1/T. В результате мы получим график, показанный на рисунке 2,в. Правая группа точек графика расположена практически на прямой линии, которая на рисунке изображена пунктиром. А это означает, что температурная зависимость константы $k(k \sim v)$ скорости растворения шипучей таблетки в воде в этом температурном диапазоне ведет себя как экспонента:

$$
k=A \exp \left(-T_{\mathrm{a}} / T\right)=A \exp \left(-E_{\mathrm{a}} /(R T)\right) .
$$

Но это есть не что иное как знаменитое уравнение Аррениуса, где $k$ - константа скорости реакции, $A$ - постоянная Аррениуса, характеризующая каждую конкретную реакцию, $E_{\mathrm{a}}=R T_{\mathrm{a}}$ - еще одна постоянная, характерная для каждой реакции и называемая энергией активации или температурой активации $T_{\text {a }}$ для температурной шкалы энергий, $R$ - универсальная газовая постоянная. Заметим, что в кинетике принято рассматривать не саму скорость реакции, а ее величину, нормированную на объем реагирующих веществ или на площадь поверхности образца, если, как в нашем случае, реакция идет на поверхности (на границе раздела фаз). Эта нормированная скорость и называется константой скорости реакции $k$. При фиксированных условиях опыта или какоголибо химического процесса скорость реакции со временем обычно уменьшается, так как реагирующие вещества расходуются в ходе реакции.

Соотношение между скоростью реакции и температурой впервые (1889 г.) установил шведский физико-химик Сванте Аррениус (1859-1927), Нобелевский лауреат по химии за 1903 год. Плодотворная идея Аррениуса, которая «сидит» в его уравнении (2), состоит в том, что «...молекулы, сталкиваясь, не реагируют, если не обладают определенным минимумом энергии, иначе говоря, энергией активации. При малой энергии активации реакции проходят очень быстро, а при высокой энергии активации химический процесс может протекать с бесконечно малой скоростью и длиться вечность. Если же в последнем случае поднять температуру настолько, что группа молекул приобретет необходи-

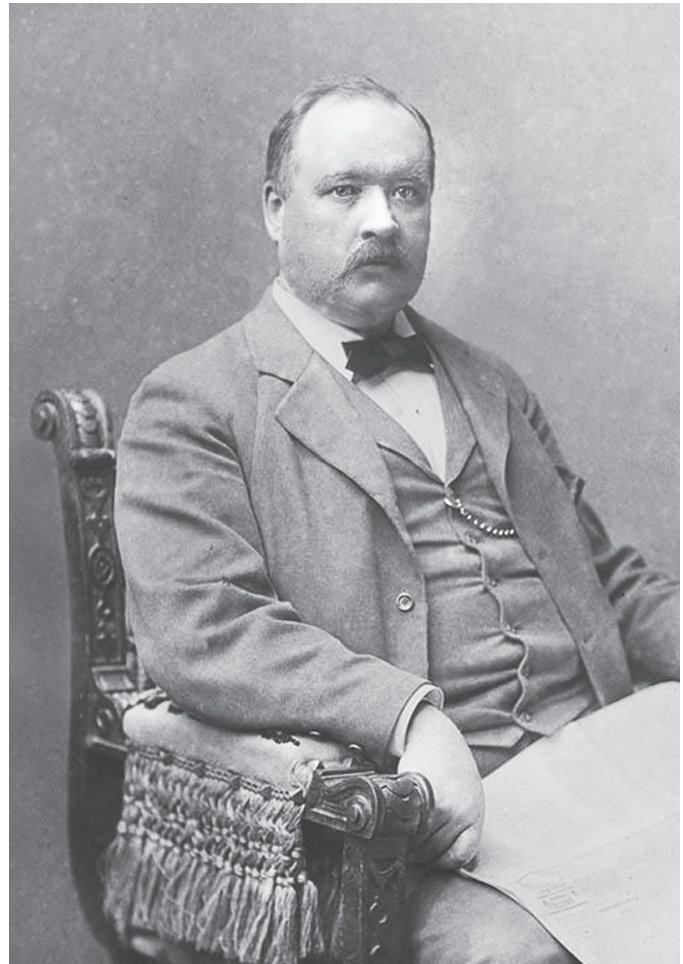

Сванте Август Аррениус

мую энергию активации, то скорость реакции может резко повыситься, и даже все закончиться взрывом...». Это мы процитировали отрывок из книги «Краткая история химии» (М.: Мир, 1983) известного ученого, популяризатора и писателя-фантаста А.Азимова.

В случае растворения шипучей таблетки аспирина в воде энергия активации из опыта получилась равной около 6900 К в температурной шкале или 57,4 кДж/моль в общепринятых единицах. В атомных единицах эта величина соответствует значению около 0,6 эВ. Относительная погрешность результата наших измерений $E_{\text {a }}$ для рассматриваемой реакции, как следует из учета разброса точек вблизи прямой на рисунке 2,в, менее $2 \%$.

Уравнение Аррениуса в истории науки занимает особое место. Оно часто используется в современных научных исследованиях в разных областях физики и химической кинетики, в технологических приложениях, например при ускоренных испытаниях долговечности интегральных схем или изучении разного рода процессов диффу- 
зии веществ в среде и на поверхности.

Формула (2) столь ценна и работоспособна, что некоторые исследователи сейчас даже уверены, что именно за ее вывод Аррениус получил Нобелевскую премию. Это не так. Премию по химии ему дали за теорию электролитической диссоциации фундаментального процесса, объясняющего природу многих химических реакций.

О работах ученых прошлого теперь мало кому известно. Часто мы забываем, что история - учитель жизни (Historia est magistra vitae). Интересно, что более века назад Аррениус, кроме всего прочего, занимался вопросами биологической химии, иммунологией, проблемами космологии и даже происхождением шаровой молнии. Он, как это ни удивительно, - автор первого учебника по космической физике. Аррениус первым сформулировал гипотезу о парниковом эффекте, столь важном для Земли, изучал влияние солнечной радиации на земную атмосферу и еще мно- гое-многое другое. Сотрудникам физфака МГУ знакома его переписка и дружба с российским ученым П.Н. Лебедевым, которому он помогал в трудное время его ухода из университета и разгона руководимой им экспериментальной группы. Аррениус поддерживал научные контакты с российскими учеными, был иностранным членом-корреспондентом Петербургской Академии наук (с 1903 г.), почетным членом Академии наук СССР (с 1925 г.).

Аррениус первым предложил использовать понятие энергии активации $E_{\mathrm{a}}$, правильно объяснив ее роль в химических реакциях, или, другими словами, раскрыл физический смысл своего уравнения. С помощью простых теоретических оценок и представлений сейчас уже несложно вывести его формулу (2). Но об этом пойдет речь во второй части статьи.

(Продолжение следует)

\section{КОНКУРС ИМЕНИ А.П.САВИНА}

Мы начинаем конкурс по решению математических задач. Задания рассчитаны в основном на учащихся начиная с 8-9 классов, а более младшим школьникам советуем попробовать свои силы в конкурсе журнала “Квантик» (см. сайт kvantik.com).

Высылайте решения задач, с которыми справитесь, электронной почтой по адресу: savin.contest@gmail.com. Кроме имени и фамилии укажите город, школу и класс, в котором вы учитесь, а также обратный почтовый адрес.

Мы приветствуем участие в конкурсе не только отдельных школьников, но и команд (в таком случае присылается одна работа со списком участников). Участвовать можно, начиная с любого тура. Победителей ждут дипломы журнала “Квант» и призы.

Задания, решения и результаты публикуются на сайте sites.google.com/view/savin-contest Желаем успеха!

1. Можно ли расставить в клетках квадрата $3 \times 3$ различные натуральные числа, в записи каждого из которых могут присутствовать лишь цифры 7 и 8 , так, чтобы сумма чисел в каждой строке и в каждом столбце была одна и та же?

\section{С.Костин}

2. а) Можно ли разрезать какой-нибудь прямоугольник на несколько равнобедренных прямоугольных треугольников, среди которых нет одинаковых? б) Можно ли так разрезать квадрат?

К.Банков
3. Есть проволочный каркас прямоугольного ящика и веревка. Разрешается выбрать любые несколько точек на каркасе, соединить их подряд натянутой веревкой и измерить ее длину - от первой точки до последней. Предложите способ за два таких измерения найти суммарную площадь всех шести граней ящика.

\section{А.Перепечко}

4. Дан треугольник $A B C$. Постройте точки $A_{1}, B_{1}, C_{1}$, образующие правильный треугольник или совпадающие, такие, чтобы отрезки $A A_{1}, B B_{1}, C C_{1}$ были равны и имели наименьшую возможную длину.

Е.Бакаев 